\title{
FAMILIAL CARDIOMYOPATHY
}

\author{
BY \\ MICHAEL BARRY AND MORGAN HALL \\ From the Ipswich Chest Clinic and the Norfolk and Norwich Hospital
}

Received February 26, 1962

Cardiomyopathy or isolated disease of heart muscle is now recognized as a common diagnostic problem. Its ætiology is unknown in many instances but in others it may be wholly or partly known. Whitfield (1961) listed instances where the ætiology is known, including endomyocardial fibrosis, amyloidosis, alcoholism, and infections by the influenza and Coxsackie viruses; in toxoplasmosis, trichinosis, trypanosomiasis, and tuberculosis; and associated with pregnancy.

In some neurological diseases with a familial incidence, cardiomyopathy has occurred. Evans and Wright (1942) reported cardiomegaly in 12 patients suffering from Friedreich's ataxia though none of their relatives suffered from cardiomegaly alone. Later Roth (1948) reported a family in which some members suffered from Friedreich's ataxia with peroneal muscular atrophy and others suffered from heart disease. Psuedo-hypertrophic muscular dystrophy has been described by Kiloh and Nevin (1951) in a family in which some members suffered from this disease alone; others had cardiomyopathy alone; and one member had both. Gordon and Hudson (1959) described one case of Refsum's disease (a familial polyneuropathy) in which cardiomyopathy occurred. These conditions however, though interesting in themselves, do not provide any help in ascertaining the factors responsible for the hereditary and familial incidence in familial cardiomyopathy.

In 1949 Evans described a syndrome to which he gave the name familial cardiomegaly: he also gave four examples where this syndrome had arisen sporadically. The clinical features include a familial incidence of cardiomegaly, palpitation, giddiness, and attacks of syncope with a tendency to arrhythmia and heart block. The cardiogram may show various types of arrhythmia and heart block and abnormalities of the QRS complex and T waves. The pathological findings are fibrosis of the myocardium and much hypertrophy of the remaining muscle fibres, with no evidence of an infective process or of any changes in the endocardium or pericardium. Battersby and Glenner (1961) suggested that familial cardiomyopathy rather than the less specific familial cardiomegaly would be a better title for what is now regarded as a clinical entity.

When the published cases of cardiomyopathy with a familial incidence are reviewed there appear to be three distinct groups, which differ from one another, mainly on pathological grounds. In the first, there is an asymmetrical hypertrophy of heart muscle, mainly involving the left ventricle and the intraventricular septum, with no great areas of fibrosis; and this hypertrophy leads to obstruction to one or other of the heart valves, most often the aorta, during contraction of the heart. Families showing these features have been described by Teare (1958), Hollman et al. (1960), and Brent et al. (1960). In the second, the pathological picture is one of hypertrophy of the cardiac muscle fibres with no evidence of fibrosis. Families fulfilling this criterion have been described in Case Records of Massachusetts General Hospital (1942), by France, Atherton, and Alsobrook (1956), and by Conway (1949). The third group is that originally described by Evans (1949) where the pathological picture of the heart muscle showed hypertrophy of the cardiac muscle fibres with large areas of fibrosis. Other families belonging to this group have been described by Paulley et al. (1956), 


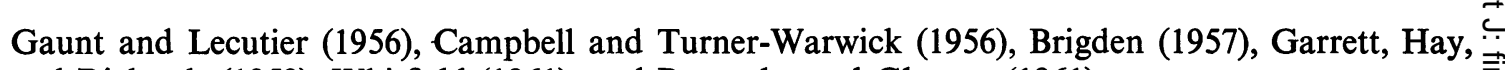
and Rickards (1959), Whitfield (1961), and Battersby and Glenner (1961).

The clinical picture in all these three groups is similar in most respects though in the first the obstruction at one or other of the heart valves caused by the hypertrophied cardiac muscle fibres, was a striking exception. These three types seem to breed true as no one family has yet been reported on where two or more of them occurred.

The family tree about to be described shows familial cardiomyopathy as it occurred in the des- $ڤ$ cendants of one man and woman through four generations. For purposes of description the family $\overrightarrow{0}$ tree in Fig. 1 has been divided into groups A, B, C, D, E, F, and G. The members of each group $\overrightarrow{\vec{\omega}}$

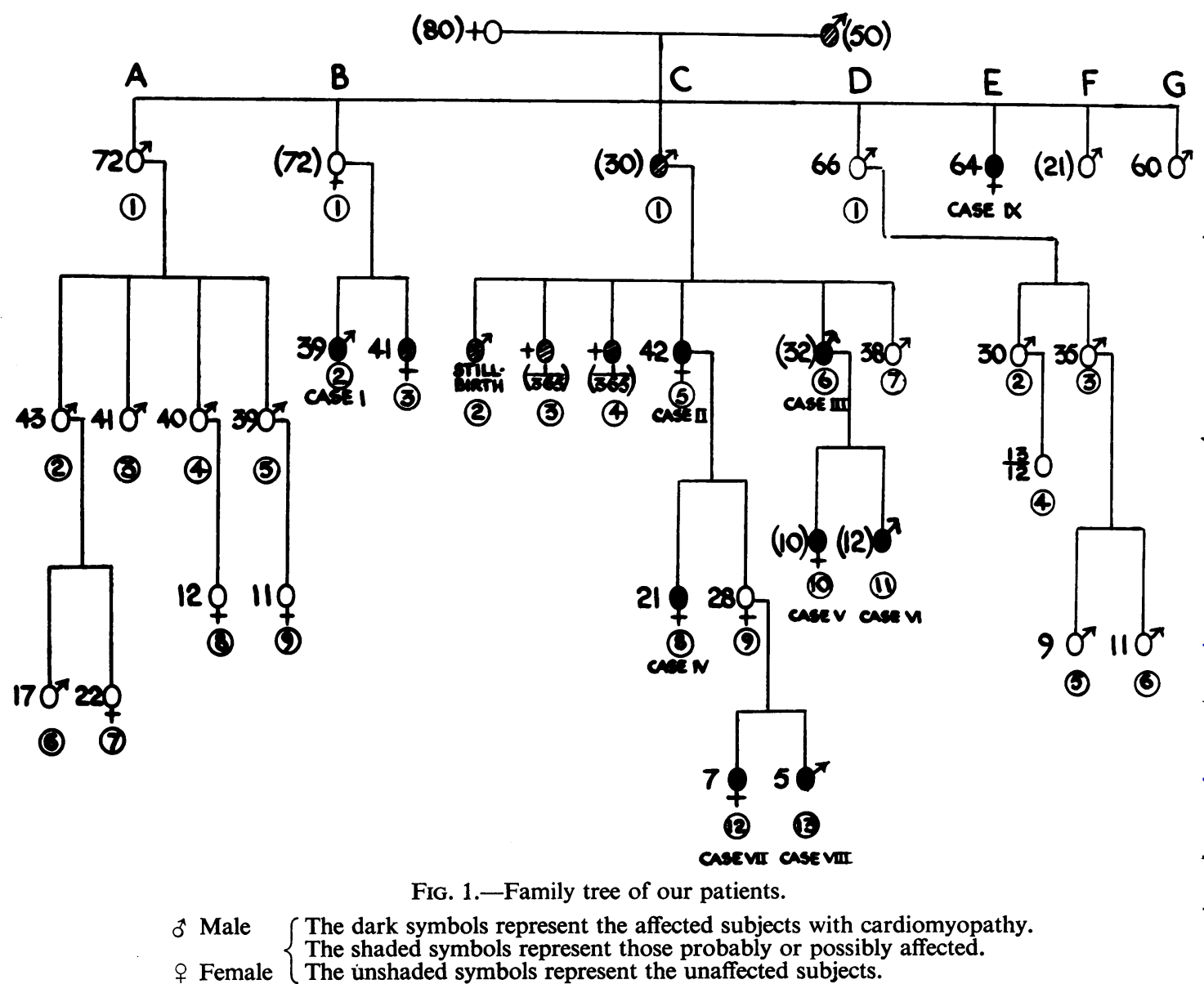

The numerals at the side of each person represent their age in years and when bracketed represent the age at death. $N$ Beneath each person are ringed numerals that indicate the position of person in each family group. The affected $N$ persons are further distinguished as Cases I, II, etc., or more fully as Cases B2 (I), C5 (II), etc.

are numbered in chronological order by means of numerals, e.g. A2, B3, etc. The affected members $\stackrel{0}{\frac{C}{D}}$ are furthermore designated as Case I, II, etc. The family groups A, D, F, and G all lived in the $\stackrel{\infty}{+}$ Slough and Staines area and the fathers of these groups all left the rural areas of Suffolk before the ${ }^{\circ}$ age of 12 years. The majority of family groups B and C lived all their lives in the rural areas of $\frac{P}{\mathbb{D}}$ Suffolk and all lived within a radius of 15 miles of one another. Cases B3 and E1 left Suffolk in $\frac{\Omega}{\square}$ their early twenties. There was no consanguinity in any of these groups but it must be admitted 
that in the areas where family groups $\mathbf{B}$ and $\mathbf{C}$ reside there is a high incidence of intermarriage over many generations: thus the parents in these groups may be more closely related than appears. No case of Friedreich's ataxia was known to occur in any member of these groups, in their spouses, or in relatives.

The forefather of all groups was a cowman who died at the age of 50 years from heart disease. For some years before his death he suffered from epileptiform attacks, and the description of these given by his eldest daughter suggests that they may have been Stokes-Adams attacks. It is therefore probable that he suffered from familial cardiomyopathy, but he has not been included as a certain case. His wife died at the age of 80 years and had spent over 30 years in a mental hospital as a certified manic depressive. No other medical history is available for either parent.

\section{FAMILY Group A}

All the members of this group were found to have normal hearts following chest X-ray, electrocardio gram, and physical examination. One member, Case A7, started at the age of 11 years to have attacks of paroxysmal tachycardia, one of which was confirmed by electrocardiogram. All members had negative serological tests for toxoplasmosis.

\section{FAMILY GROUP B}

This consists of a mother and her son and daughter.

Case $B 1$ worked as a housewife and was married to a cowman. She gave a history of attacks of syncope and palpitation since the age of 19, at which time she had been told her heart was enlarged. When first seen at the age of 71, she was in congestive heart failure and had been under treatment for this for two years. Her blood pressure was $160 / 95 \mathrm{~mm}$. Hg. She had a varying P-R interval, inversion of T waves over leftsided leads, normal QRS complexes and at times sinu-atrial block. In the chest radiograph the heart was found to be grossly enlarged with a cardiothoracic ratio of 63 per cent with apparent enlargement of all chambers. There was also hilar congestion and signs of congestion in both lungs. The toxoplasma serology showed a dye test titre of $1 / 8$ with a negative complement-fixation test.

One year later she developed atrial fibrillation and subsequently died from a cerebral embolus.

Necropsy. Heart weight, 620 g.; coronary arteries normal; marked dilatation of right side of heart; myocardium flabby and friable. Extensive infarction of left cerebral hemisphere in the fronto-parietal region.

Microscopically, the heart muscle showed interstitial œdema and loose fibrosis with no hypertrophy of muscle fibres. The picture was that of a mild subacute myocarditis.

Case B2 (I). A man, aged 39, married but with no children, worked as a van driver. Since his early teens he had always been more breathless on exertion than others of his age. He volunteered for military service in 1940 but when asked to do a simple exercise he became very breathless and was referred to a panel of doctors who were unable to find any organic cause for his dyspnœa: as he was very anxious to serve he was passed fit for service. Early in his army service he was unable to keep up with other recruits and was posted to a unit as a driver, where he served for six years. Since his discharge he has been unable to do any work where physical effort of any degree is required, but is otherwise symptom free. His blood pressure was $130 / 90 \mathrm{~mm}$. $\mathrm{Hg}$, there were no heart murmurs, and his rhythm was regular. His cardiogram showed sinus rhythm with a L.A.D. of -15; large bifid P waves in leads I, II, AVR, AVF, and V1-V6; and a P-R interval prolonged to $0.21 \mathrm{sec}$. The QRS complex showed some widening with Q waves in leads I and AVL and negative $T$ waves in these leads. The pattern suggested lateral ischæmia. His chest radiograph shows a cardiothoracic ratio of 54 per cent with a small aortic knuckle. His toxoplasma serology showed negative dye and complement-fixation tests.

Case B3. A woman aged 44 years who had worked as a domestic servant. She is at present in a mental hospital and is a certified manic depressive for the past 15 years. Her blood pressure was $140 / 90 \mathrm{~mm}$. $\mathrm{Hg}$ and there were no abnormal physical signs in her cardiovascular system apart from signs of some enlargement of her heart. Her cardiogram was normal. Her chest radiograph showed a cardiothoracic ratio of 53 per cent with a normal aortic knuckle. Her toxoplasma serology showed a dye test titre of $1 / 32$ with a negative complement-fixation test. It is possible that she may have a cardiomyopathy though the cardiographic findings do not support it. 


\section{FAMILy Group C}

This group of families contains the greatest number of cases of cardiomyopathy (Cases II-VIII).

Case C1. The forefather of this group of families was a cowman. His medical history showed nothing of importance until, when aged 30, he was admitted to a mental hospital in a state of acute mania, with at the same time congestive heart failure and a large heart. His blood pressure was $120 / 80 \mathrm{~mm}$. $\mathrm{Hg}$ and there were no heart murmurs. Three weeks after admission he died suddenly. Death was certified as due to acute mania and dilatation of the heart, but no necropsy was performed. It is probable that he suffered from familial cardiomyopathy, but he has not been included as a certain case.

Case C2. This, the first-born male child of Case C1, was stillborn. It is possible that this child was affected by a cardiomyopathy.

Cases $C 3$ and $C 4$ were the second and third children of Case C1. Both were female and both lived only one day. No necropsy was performed. There is a possibility that both suffered from a familial cardiomyopathy.

Case C5 (II). The fourth child of Case C1 was a housewife, aged 42, who had a history of attacks of syncope and palpitation since her early twenties. She also suffered from moderate dyspnœa. On examination she had a systolic murmur (Grade 1) in the aortic and pulmonary areas and down the left side of the sternum and a blood pressure of $135 / 85 \mathrm{~mm}$. $\mathrm{Hg}$. The cardiogram showed sinus rhythm with a normal axis; large P waves in leads I, II, AVR, AVL, AVF, tending to be bifid; a $35 \mathrm{~mm}$. S wave in V2 and a $20 \mathrm{~mm}$. R wave in V6; and T waves that were inverted in leads III and AVF and very large in leads V2-V5, reaching a height of $11 \mathrm{~mm}$. in V3 and V4. The pattern was one of left ventricular hypertrophy. Her chest radiograph (Fig. 2) showed a cardiothoracic ratio of 54 per cent, a small aortic knuckle, and a right atrium that appeared enlarged. The toxoplasma serology showed a dye test titre of $1 / 64$ with a negative complement-fixation test. Her husband who worked as a cowman was found to have no abnormality in his cardiovascular system.

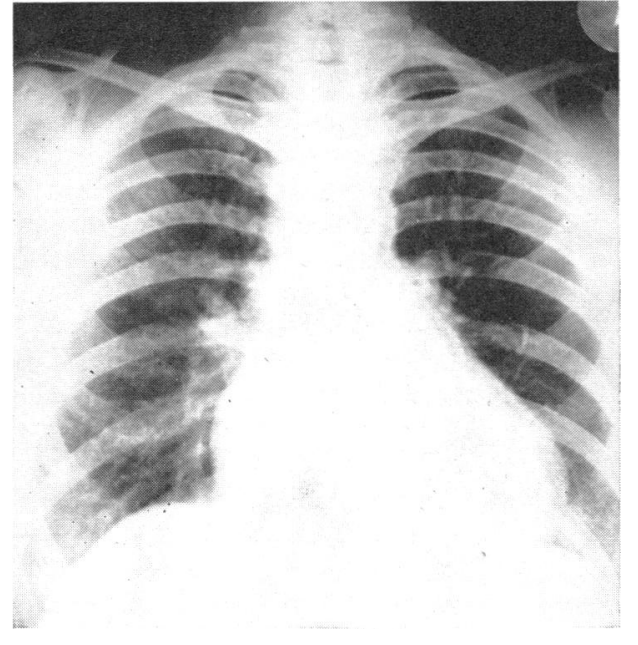

FIG. 2.-Case C5 (II), aged 42 years. Generalized cardiomegaly.

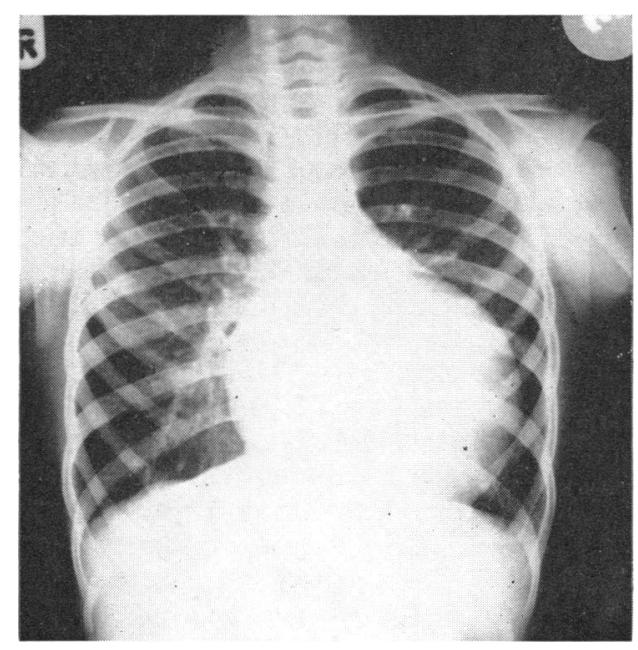

FIG. 3.-Case $\mathrm{C} 10(\mathrm{~V})$, aged 10 years. Cardiomegaly with enlarged right atrium and ventricular mass with small aortic knuckle.

Case C6 (III). The fifth child of Case C1. He worked as a cowman, and there was no previous medical history before he collapsed and died suddenly at the age of 32 years.

Necropsy. The only abnormality found was gross enlargement of the whole heart with hypertrophy of the heart muscle in all the chambers, particularly marked in the left ventricle. The muscle of both the right and left ventricles showed patchy grey areas of fibrosis throughout and was very firm. Both the pericardium and endocardium were normal as were the coronary arteries and aorta.

Histological Examination. Sections of the myocardium of ventricles showed patchy irregular replacement of muscle fibres by dense fibrous tissue. The remaining muscle fibres were greatly hypertrophied; 
some showed patchy areas of degeneration and many showed the appearance of being partly merged into the surrounding fibrous tissue. The collagen fibres were all arranged in the line of the muscle fibres. No true vacuolization of the muscle fibres was seen and no excess glycogen could be demonstrated. Muscle striations were fairly well preserved in most of the fibres. There was hypertrophy of the media of the small arteries with plentiful elastic tissue. There was no evidence of arteritis.

Case C7. The sixth child of Case $\mathrm{C1}$, he was 38 and was a farmworker. Chest radiograph, cardiogram, and physical examination revealed no abnormality. The only relevant medical history obtained was that he had spent a period in a mental hospital suffering from a manic depressive psychosis.

Case C8 (IV). The daughter of Case C5 (II), she is 21, married, but has no children. Her only symptom is slight dyspnoea on exertion. On examination she had a grade 2 systolic ejection murmur maximal in pulmonary area. There was also a systolic thrill in 3rd and 4th left interspaces and slight right ventricular lift. The physical signs suggest that there is some hypertrophy of the outflow tract of right ventricle, but it does not seem to be causing significant obstruction to pulmonary outflow. The second sound moved normally. The cardiogram showed sinus rhythm with a normal axis; large P waves in leads I, II, AVR, AVL, and AVF; a $Q$ wave of $5 \mathrm{~mm}$. in lead III, S waves of $25 \mathrm{~mm}$. and $30 \mathrm{~mm}$. respectively in leads V1 and V2, and an R wave of $15 \mathrm{~mm}$. in V6; and depression of the S-T segment in leads I, II, AVL, and V4-6. The pattern was that of left ventricular hypertrophy. Chest radiograph suggested generalized cardiac enlargement with a cardiothoracic ratio of 51 per cent. The toxoplasma serology showed negative dye and complement fixation tests.

Case C9. A housewife of 28 years, a daughter of Case II, with two children. Her heart was found to be normal from chest radiograph, cardiogram, and physical examination. Her husband, a farmworker, also had a normal heart.

Case $C 10(V)$. The daughter of Case III, she was a schoolgirl aged 10 years when her heart lesion was discovered by mass miniature radiography. She had no symptoms. On examination she had a grade 2 systolic murmur in the aortic and pulmonary areas and down the left side of sternum. There was also a paradoxical split of the second sound. Her blood pressure was $100 / 70 \mathrm{~mm}$. Hg. The cardiogram showed sinus rhythm with a L.A.D. of -30, with large P waves in leads I, II, AVR, and AVL. The QRS complexes were very large and the sensitivity had to be reduced to half normal to record the complexes in V3-6: in leads V4-V6 the $R$ and $S$ components were of equal size, being $15-20 \mathrm{~mm}$. in height; and there was a $3 \mathrm{~mm}$. $Q$ wave in lead III. The T waves were very large in leads I, II, III, AVR, AVF, and V3-6 and reached a height of $13 \mathrm{~mm}$. in lead II. The pattern was that of biventricular hypertrophy. Chest radiograph showed enlargement of all chambers of the heart with a small aortic knuckle and the cardiothoracic ratio was 62 per cent (Fig. 3). The toxoplasma serology showed negative dye and complement-fixation tests. Ten months after she was first seen, she died suddenly while getting on the school bus.

Necropsy. The only abnormal pathological features to be found were in the heart. This weighed $560 \mathrm{~g}$. and showed gross concentric hypertrophy and moderate dilatation of the left ventricle, and moderate hypertrophy of the right ventricle (Fig. 6). The endocardium and pericardium were both normal.

Microscopical sections of the left ventricle showed a network of fibrous tissue separating groups and surrounding individual muscle fibres. The muscle fibres were hypertrophied and striations were fairly well preserved in most of the fibres. Degenerative changes were seen in some of them, and in the more dense area of fibrosis some muscle fibres appeared to merge into the collagenous tissue. No vacuolation or excess glycogen were demonstrated. The small arteries showed hypertrophy of the media with plentiful intact elastic tissue. There was no evidence of arteritis. The ventricular septum showed a similar appearance. The same but lesser changes were seen in the right ventricle and in the atria. The endocardium and pericardium were both normal (Fig. 7 and 8).

Special Staining. This revealed abnormal accumulations of muco-polysaccharide within the muscle fibres. The material stained brilliantly with periodic acid Schiff and resisted digestion with saliva. It did not stain with Alcian blue nor was it metachromatic, which suggests neutral polysaccharide and excludes glycogen. The material was seen as granules about 1 or $2 \mu$ in diameter concentrated in focal collections particularly in the perinuclear region. In some areas this material appeared as a homogeneous sheet about $20 \mu$ in width, replacing the whole width of the muscle fibre. Such an appearance might be seen in roughly 1 in 25 fibres in a line across the section. The granules were more common but were not found in every fibre. No abnormal accumulations of this material were seen in the intercellular spaces although in one or two sites an accumulation of the material seemed to have been associated with loss of cell outline and therefore to be lying free. Granules of lipofuscin, which increase in heart muscle fibres with age, although about the same size as those seen in this case, do not stain with periodic acid Schiff. 


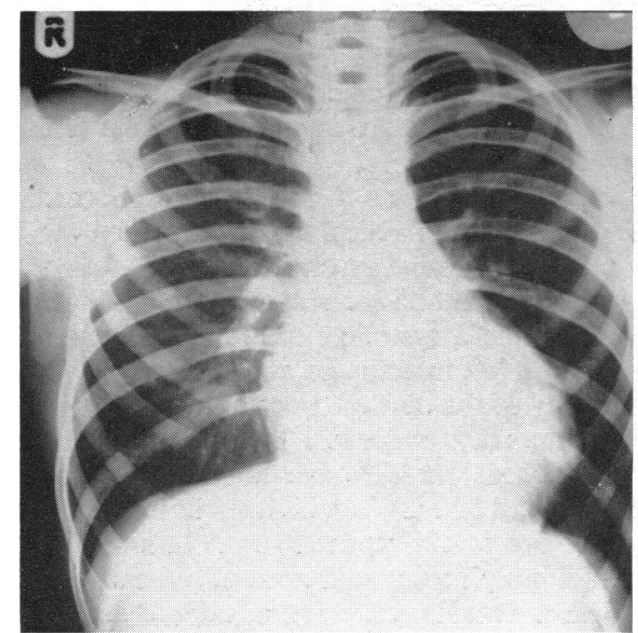

FIG. 4.-Case C11 (V1), aged 12 years. Cardiomegaly with large right atrium and small aortic knuckle.

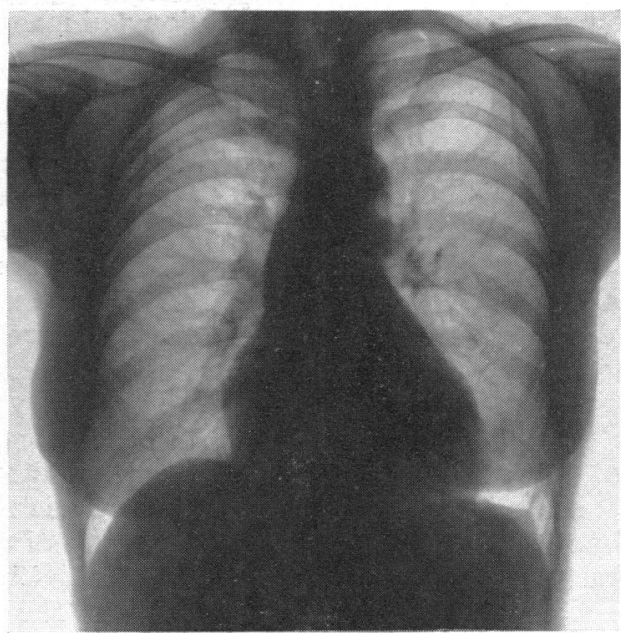

Fig. 5.-Case E1 (IX), aged 64 years. Generalized cardiac enlargement with small aortic knuckle.

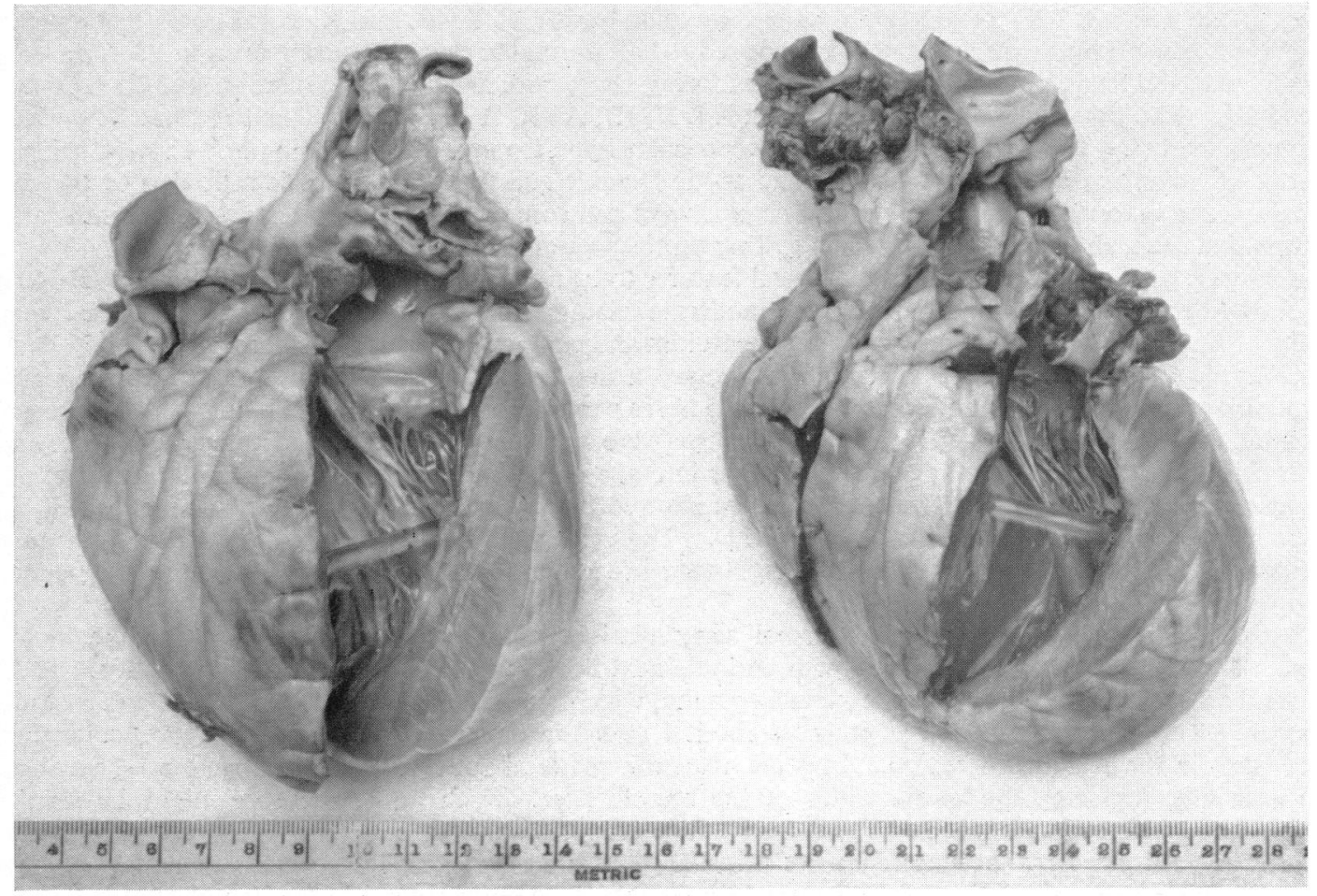

Fig. 6. -The heart of Case C11 (V1) is on the left and the heart of Case C10 (V) is on the right. The hypertrophy of the left ventricle in both patients is well shown. 


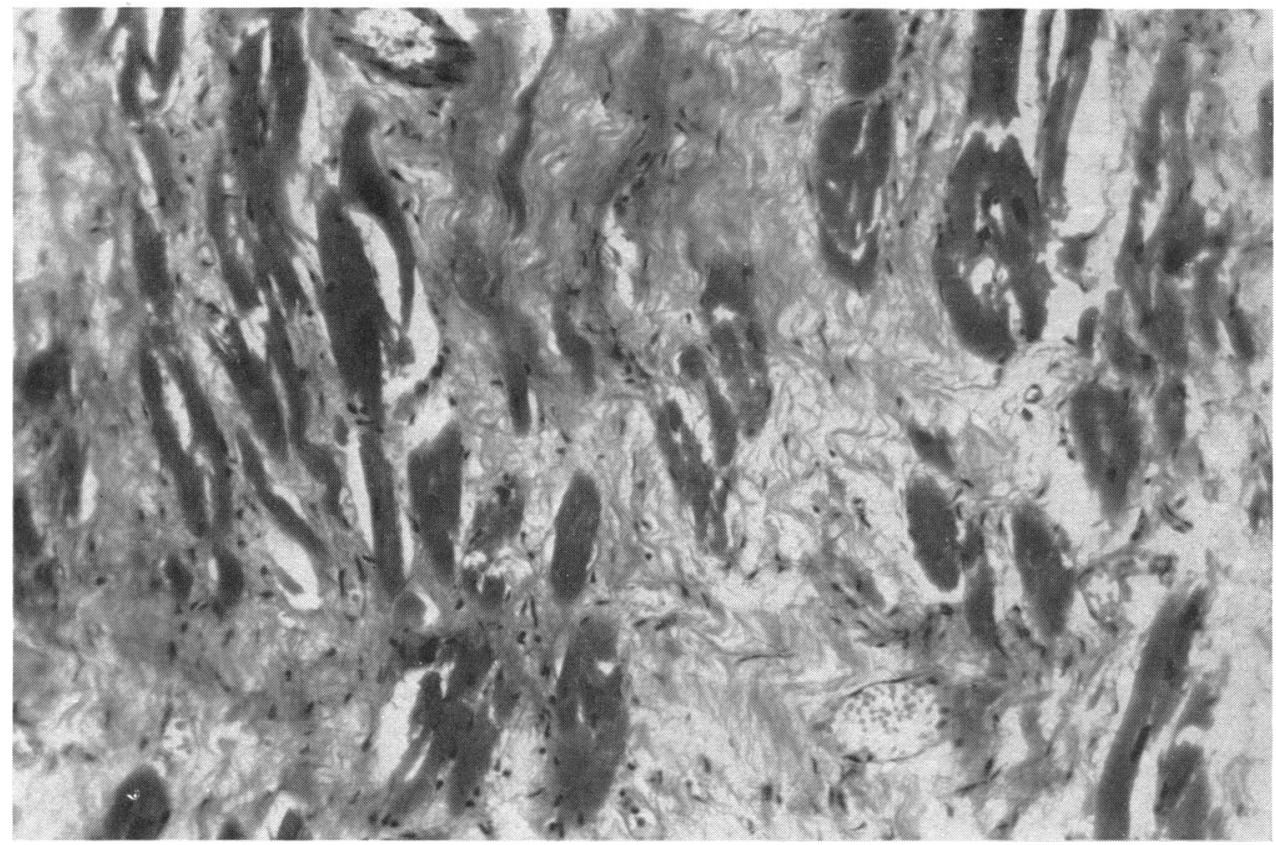

FIG. 7.-Photomicrograph $(\times 250)$ of myocardium of left ventricle of Case $\mathrm{C} 10(\mathrm{~V})$ showing hypertrophy of the muscle fibres and extensive areas of fibrosis.

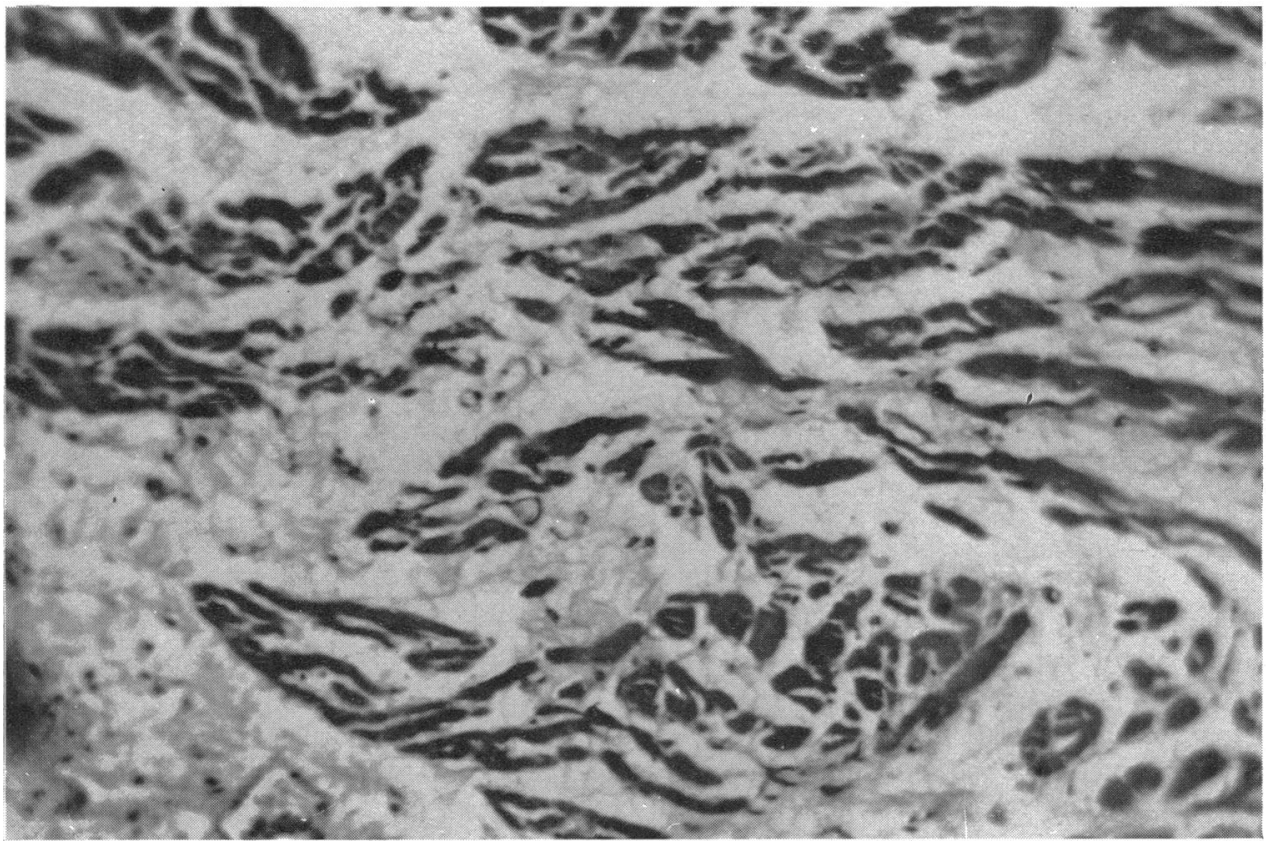

Fig. 8.-Photomicrograph $(\times 250)$ of myocardium of right ventricle of Case $\mathrm{C} 10(\mathrm{~V})$ showing areas of fibrosis and hypertrophy of muscle fibres. 
Case CII (VI). The son of Case III, he was a schoolboy aged 12 when his heart was first queried as a result of mass miniature radiography. His only symptom was moderate dyspnœa on exertion and this was spasmodic. He was seen once at a local children's hospital and diagnosed as an asthmatic. He has always been more breathless on exertion than others of his age. On examination he had a grade 2 pansystolic murmur in the pulmonary area and down the left side of sternum and at the apex. It was maximal in the 3rd and 4th left interspaces. There were no thrills and the second sound moved normally and his blood pressure was $110 / 65 \mathrm{~mm}$. Hg. The cardiogram showed sinus rhythm with a L.A.D. of $-15^{\circ}$; large $\mathrm{P}$ waves in leads I and AVL; Q waves of $4 \mathrm{~mm}$. in lead I and of $7 \mathrm{~mm}$. in AVL; and very large QRS complexes in all leads, particularly I, II, and V1-V6, the R and S waves being of equal size in leads V4-V6. There was depression of S-T segments in leads I, AVL, and V2-V6, and the T waves were large in leads II, AVR, and V2-6. The pattern was that of biventricular hypertrophy. His chest radiograph showed enlargement of all chambers of the heart with a small aortic knuckle and the cardiothoracic ratio was 57 per cent (Fig. 4). Three months after he was first seen he died suddenly on his way home from school.

Necropsy. The only abnormal findings were those found in the heart, which weighed $540 \mathrm{~g}$. with gross hypertrophy and dilatation of left ventricle. The muscle was very firm and pale (Fig. 6). The endocardium and pericardium seemed to be normal.

Microscopically, the sections of the heart muscle (Fig. 9) showed the same changes as seen in his sister Case $\mathrm{V}$ and this was also the case with the special-staining.

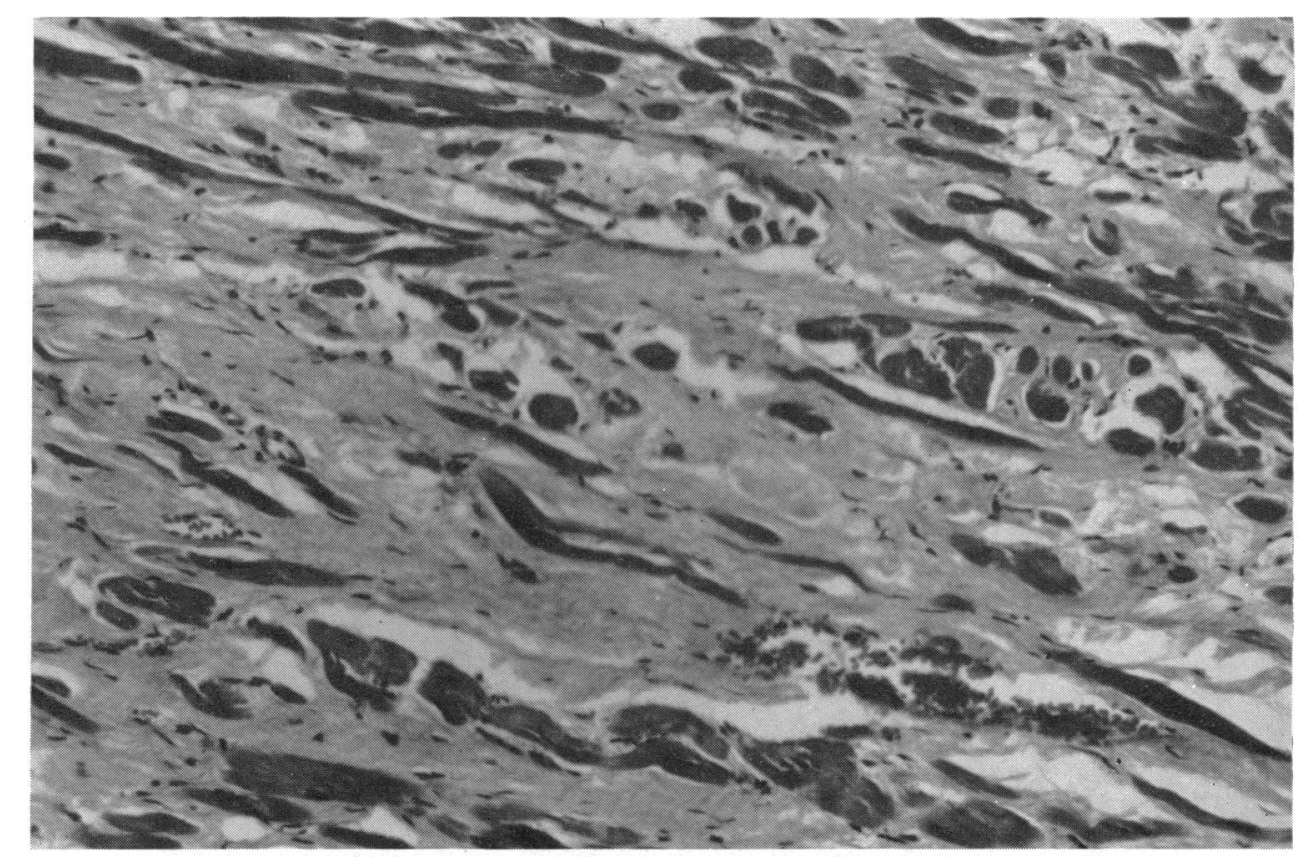

FIG. 9.-Photomicrograph $(\times 250)$ of myocardium of left atrium of Case C11 (V1) showing less extensive fibrosis and hypertrophy of muscle fibres when compared with Fig. 7.

Case C12 (VII). The daughter of Case C9, she is a schoolgirl aged 7 years and had no symptoms. On examination she had a grade I systolic murmur in the pulmonary and aortic areas and at the apex. The murmur at the apex was late systolic and was attributed to the mitral valve. Her blood pressure was $100 / 75 \mathrm{~mm}$. Hg and the second sound moved normally. The cardiogram showed sinus rhythm with a normal axis; large P waves in leads I, II, AVR, and AVL; Q waves in leads II, III, and AVF; and normal QRS complexes. The pattern was normal apart from the abnormal $\mathrm{P}$ and $\mathrm{Q}$ waves. Her chest X-ray showed some enlargement with a cardiothoracic ratio of 50 per cent. The toxoplasma serology showed negative dye and complement-fixation tests. 
Case C13 (VIII). He is the son of Case $\mathrm{C} 9$ and is a schoolboy, aged 5 years, and has no symptoms. On examination he had a Grade I systolic ejection murmur in the pulmonary and aortic areas. The murmur was maximal in the pulmonary area and the second sound moved normally. There was also a third heart sound at the apex. His blood pressure was $95 / 80 \mathrm{~mm}$. $\mathrm{Hg}$. The cardiogram showed sinus rhythm and a normal axis; a Q wave of $4 \mathrm{~mm}$. in lead III and a small Q wave in AVF; and large T waves in leads I, II, and AVR. Chest radiographs showed a cardiomegaly with a cardiothoracic ratio of 55 per cent. The toxoplasma serology showed negative dye and complement-fixation tests.

\section{FAMily Groups D, E, F, AND G}

All the members of group D were found to have normal hearts following radiological, cardiographic, and physical examination. Case D1 had a toxoplasma dye test titre of $1 / 16$ and Case D2 one of $1 / 32$ but both had negative complement-fixation tests.

Case E1 (IX) was the only member in this group. A woman, aged 64 years, had worked as a domestic servant and was unmarried. She has resided in a mental hospital for some 20 years and was originally admitted for a neurotic depression. At the present time she is living in the mental hospital as a voluntary patient. She has no symptoms referable to her cardiovascular system. On examination, no murmurs were heard, she was in sinus rhythm, and had a blood pressure of $130 / 90 \mathrm{~mm}$. Hg. The cardiogram showed sinus rhythm with an occasional ventricular extrasystole; left axis deviation of $-60^{\circ}$; large and bifid $P$ waves in leads II and AVR and a P-R interval of $0.24 \mathrm{sec}$; Q waves of $3 \mathrm{~mm}$. in leads III and AVR; a QRS duration of $0.12 \mathrm{sec}$; and T waves that were negative in leads I and AVL and abnormally large in leads III, AVL, and AVF. The pattern was that of intraventricular block. The chest radiograph showed a cardiomegaly with a cardiothoracic ratio of 54 per cent and a small aortic knuckle (Fig. 5). The toxoplasma serology showed a dye test titre of $1 / 64$ with a complement-fixation titre of $1 / 8$.

The only person in group $\mathrm{F}$ was killed in the first World War.

The only person in group $\mathrm{G}$ was found to have a normal heart following radiological, cardiographic, and physical examination. Though married, he had no children. His toxoplasma serology showed a dye test titre of $1 / 32$ with a negative complement-fixation test.

\section{Discussion}

The family tree just described showed 9 certain members who had a cardiomyopathy, and 6 others possibly or probably with the same condition. It must be admitted that Case B3 is doubtful as her cardiogram was normal despite radiological evidence of cardiomegaly. The dangers of assuming that a patient suffers from a particular form of cardiomyopathy on clinical and radiological evidence alone without post-mortem controls is well illustrated by Case B1. This patient had the history, radiological evidence of a gross cardiomegaly, and some cardiographic findings that seemed to denote that she too suffered from familial cardiomyopathy, though necropsy showed signs suggesting subacute myocarditis. However, her heart was so enlarged that to accept the diagnosis one would have expected grosser changes in her cardiogram than were actually present.

The symptomatology of the patients in these families was not very dramatic. Five of them were symptom free (Cases III, V, VII, VIII, and IX) but despite lack of symptoms sudden death occurred in Cases III and V. Dyspnœa alone of varying degrees occurred in three (Cases I, IV, and VI) but was paroxysmal in Case VI. Symptoms of dyspnœa, syncope, and palpitation occurred in one (Case II). Both Cases V and VI were seen within one month of their sudden deaths and there was no change in symptomatology or cardiographic findings. The presence or absence of symptoms does not appear to give any guide to the prognosis in these cases.

The electrocardiograms of these patients (Table I) did not show the conduction defects described in families reported by Evans (1949), Gaunt and Lecutier (1956), and Campbell and Turner-Warwick (1956). Our findings were more in keeping with those described by Brigden (1957) and Whitfield (1961). Only one case in these families showed a conduction defect (Case IX) and her cardiogram showed intraventricular block. The cardiograms showed evidence of biventricular hypertrophy in Cases V and VI; of left ventricular hypertrophy in Cases II and IV; and of lateral ischæmia in 
TABLE I

ELECTROCARDIOGRAPHIC Findings

\begin{tabular}{c|l|l|l|l}
\hline \begin{tabular}{c|l} 
Case \\
No.
\end{tabular} & Rhythm & Q waves & Abnormal P waves & Abnormal T waves \\
\hline II & Sinus & I, AVL & I, II, AVR, AVF, V1-6 & I, AVL \\
II & Sinus & none & I, II, AVR, AVL, AVF & III, AVF, V2-5 \\
IV & Sinus & III & I, II, AVR, AVL, AVF & None \\
V & Sinus & III & I, II, AVR, AVL & I, II, III, AVR, AVF, V3-6 \\
VI & Sinus & I, AVL & I, AVL & II, AVR, V2-6 \\
VII & Sinus & II, III, AVF & I, II, AVR, AVL & None \\
VIII & Sinus & III, AVF & None & I, II, AVR \\
IX & Sinus & III, AVR & II, AVR & I, III, AVL, AVF \\
\hline
\end{tabular}

Case I. In the remainder there were abnormalities of the $\mathrm{P}$ and $\mathrm{T}$ waves with abnormal $\mathrm{Q}$ waves.

Systolic murmurs occurred in 6 patients. In Cases II, V, and VI they were heard in the aortic and pulmonary areas and down the left side of sternum. The murmurs varied in intensity and length being pansystolic in Case VI. In Case VII the murmur appeared to arise from the pulmonary valve and in Case VIII from the mitral valve. The murmur in Case IV suggested muscular infundibular pulmonary stenosis of minor degree.

There were 4 patients with manic depressive psychosis in the families-Cases B3, C1, and C7 and the wife of the forefather of all these family groups. A neurotic depression occurred in Case IX. This may be an incidental finding but may be significant though it has not previously been reported.

The pathological findings (Fig. 7, 8, and 9) in the 3 patients who came to necropsy (Cases III, V, and VI) were very similar. All showed areas of dense fibrosis with hypertrophy of the remaining muscle fibres. No vacuolization of muscle fibres was seen in any of them though it was looked for particularly in Cases V and VI. All four chambers of the heart were involved and the fibrosis and hypertrophy were maximal in the left ventricle and minimal in the atria. The interventricular septum was involved in Cases V and VI. There was hypertrophy of the media of the smaller arteries in the heart muscle with plentiful elastic tissue in the three cases. By special staining methods a neutral polysaccharide was demonstrated within the muscle fibres. It occurred both as granules and sheets. Battersby and Glenner (1961) had previously reported plaques of a neutral polysaccharide within the muscle fibres but this is the first time granules of the material have been found. This might be explained by the youth of the patients in whom the granules were demonstrated and might represent an early phase of the same process.

It has been suggested by Paulley et al. (1956) that toxoplasmosis might be a factor in the ætiology of this condition. With this possibility in mind nearly all the members of this family tree either affected or unaffected had serological tests for toxoplasmosis. Positive dye tests of a titre of $1 / 32$ occurred in two of the unaffected members with negative complement-fixation tests. In Case II, there was a positive dye test titre of $1 / 64$ with a negative complement-fixation test. In Case IX there was a positive dye test titre of $1 / 32$ with a complement-fixation test titre of $1 / 6$ : this is probably not significant in view of the low titres and the report by Whitfield (1961) that common conditions such as trichomonas infection can give rise to positive complement-fixation tests. Isolated cases of cardiomyopathy may on occasions be due to infection with toxoplasma, but as a causative factor toxoplasmosis seems to be excluded as far as this group of families is concerned. Reports of other families with this complaint also deny the possibility.

The environment of the affected family groups might be significant in the ætiology of this disease. The fathers of family groups A, D, and G all left the rural areas of Suffolk in their youth and settled in the urban areas of Slough and Staines: none of their descendants developed a cardiomyopathy and their spouses and their children's spouses all came from urban areas. There was no obvious consanguinity in any of the affected families, but owing to the amount of intermarriage that takes place 
in these rural areas over successive generations the parents may be more closely related to one another than is presently obvious. The spouses of Cases II and III and C9 were themselves examined and found to have no cardiac abnormality nor was there any history of heart disease in any of their relatives. The mode of inheritance in these families appears to be through a Mendelian dominant gene with incomplete penetrance.

The ætiology of familial cardiomyopathy is now generally regarded as genetic. The factors still unknown are those responsible for the familial incidence and the exact defect causing the lesions in the heart muscle. Most published families suggest that the mode of transmission is by a Mendelian dominant gene. However, Battersby and Glenner (1961) thought a recessive genetic inheritance was the mode of transmission in their cases. The assertion, with reservations, by Whitfield (1961) that transmission only occurs through the female is now known to be false and the disease is not sex limited.

The cause of the lesions in the heart muscle is still unknown. Paré et al. (1961) considered that familial cardiomyopathy was the result of an inherited defect in development involving the myocardium and the larger arteries, and instanced the hypoplasia of the aorta as some evidence in favour of their contention. Hayes, Dimond, and Crockett (1959), however, considered that hypoplasia of the aorta in their case was secondary to the cardiomyopathy. This is the more likely explanation as cases of familial cardiomyopathy are known to have a low cardiac output and similar hypoplasia of the aorta occurs in other congenital and acquired heart conditions where the cardiac output is low.

It seems possible that ischæmia of heart muscle due to abnormalities in the smaller arteries and arterioles could be a factor in the ætiology of the lesions found in familial cardiomyopathy. Brigden (1957) suggested that if heart muscle was damaged hypertrophy of the remaining fibres was a nonspecific response to normal hæmodynamics. Lesions of a minor degree were found in the small arteries and arterioles in our cases and more severe lesions in these vessels were reported by Battersby and Glenner (1961). However, they considered that these lesions were not the responsible factor in the ætiology of lesions in the cardiac muscle but were secondary to a metabolic defect in the cardiac muscle.

In our cases, a non-metachromatic neutral polysaccharide was found in muscle fibres: it appeared in two forms as granules and sheets. Battersby and Glenner (1961) reported plaques of this material in their cases and considered this metabolic change was the inherited defect producing the lesions in cardiac muscle. Other defects in the metabolism of cardiac muscle were reported by Evans (1949), Elster, Horn, and Tuchman (1955), and Gaunt and Lecutier (1956). In their cases there was marked vacuolization of, and abnormal deposits of glycogen in, the cardiac muscle fibres. Furthermore Evans (1949) and Gaunt and Lecutier (1956) also reported abnormal deposits of glycogen in the vestus externi muscles of their cases.

The published evidence suggests that the ætiology of the lesions in cardiac muscle is probably due to an inherited metabolic defect in the cardiac muscle. The different modes of inheritance seen in published families may be explained by the possibility of several different metabolic defects producing the same pathological end picture in cardiac muscle.

\section{SUMMARY}

A group of families, the descendants of one couple through four generations, is described. In these families 9 cases of familial cardiomyopathy were discovered, and 6 other probable cases. Five of these 15 have died suddenly, while two lived one day and a third was stillborn. The remaining seven are still alive, and four of them have no symptoms. The environment of these families is discussed and also the clinical, radiological, electrocardiographic, and pathological findings.

The mode of inheritance in these families appears to be due to a Mendalian dominant gene with incomplete penetration. The possibility of a recessive gene being responsible has been eliminated as far as possible. 
A metabolic defect in cardiac muscle has been demonstrated in two of the cases coming to necropsy. This consisted of the finding of a non-metachromatic neutral polysaccharide in the cardiac muscle fibres.

The atiology of this condition is reviewed, and it is suggested that the cause of this condition is an inherited metabolic defect in cardiac muscle.

We are greatly indebted to the general practitioners in Slough and Staines areas and East Suffolk for their help and co-operation in allowing us access to their patients; to Dr. B. Thompson of Upton General Hospital, Slough, for the use of his clinic; to Dr. G. R. Birnie of St. Bernards Hospital, Southall, Dr. I. Atkin of Park Prewett Hospital, Basingstoke, and Dr. P. McCauley of St. Audrey's Hospital, Melton, for details of patients under their care; to Dr. A. Lintott of Ipswich and East Suffolk Hospital, Ipswich, for autopsy report on Case B1; to Dr. G. B. Ludlam for the toxoplasma serological tests; to Dr. Lynne Reid of Brompton Hospital, London, for the special staining; and to Dr. H. A. Fleming of Papworth Hospital, Cambridge, for his valuable guidance.

\section{REFERENCES}

Battersby, E. J., and Glenner, G. G. (1961). Familial cardiomyopathy. Amer. J. Med., $30,382$.

Brent, L. B., Aburano, A., Fisher, D. L., Moran, T. J., Myers, J. D., and Taylor, W. J. (1960). Familial muscular subaortic stenosis; an unrecognized form of "idiopathic heart disease" with clinical and autopsy observations. Circulation, 21, 167.

Brigden, W. (1957). Uncommon myocardial diseases: the non-coronary cardiomyopathies. Lancet, 2, 1179 and 1243.

Case Records of Massachusetts General Hospital (1942). Idiopathic hypertrophy and dilatation of heart (Cabot case 28042). New Engl. J. Med., 226, 158.

Campbell, M., and Turner-Warwick, M. (1956). Two more families with cardiomegaly. Brit. Heart J., $18,393$.

Conway, D. J. (1949). A case of congenital idiopathic hypertrophy of the heart. Arch. Dis. Childh., 24, 195.

Elster, S. K., Horn, H., and Tuchman, L. R. (1955). Cardiac hypertrophy and insufficiency of unknown etiology: a clinical and pathologic study of 10 cases. Amer.J. Med., 18, 900.

Evans, W. (1949). Familial cardiomegaly. Brit. Heart J., 11, 68.

- and Wright, G. (1942). The electrocardiogram in Friedreich disease. Brit. Heart J., 4, 91.

France, R. F., Atherton, C. W., and Alsobrook, W. L. (1956). Fatal congestive heart failure associated with cardiac enlargement of unexplained origin. Circulation, 14, 373.

Garrett, G., Hay, W. J., and Rickards, A. G. (1959). Familial cardiomegaly. J. clin. Path., $12,355$.

Gaunt, R. T., and Lecutier, M. A. (1956). Familial cardiomegaly. Brit. Heart J., 18, 251.

Gordon, N., and Hudson, R. E. B. (1959). Refsum's syndrome: heredopathia atactica polyneuritiformis: a report of three cases, including a study of the cardiac pathology. Brain, 82, 41 .

Hayes, W. L., Dimond, E. G., and Crockett, J. E. (1959). Idiopathic cardiomegaly with extreme cardiac enlargement. Amer. J. Cardiol., 4, 528.

Hollman, A., Goodwin, J. F., Teare, D., and Renwick, J. W. (1960). A family with obstructive cardiomyopathy (asymmetrical hypertrophy). Brit. Heart J., 22, 449.

Kiloh, L. G., and Nevin, S. (1951). Pseudohypertrophic muscular dystrophy with cardiomegaly. Proc. roy. Soc, Med., 44, 694.

Paré, J. A. P., Fraser, R. G., Pirozynski, W. J., Shanks, J. A., and Stubington, D. (1961). Hereditary cardiovascular dysplasia. Amer. J. Med., 31, 37.

Paulley, J. W., Jones, R., Green, W. P. D., and Kane, E. P. (1956). Myocardial toxoplasmosis. Brit. Heart J., 18, 55.

Roth, M. (1948). On a possible relationship between hereditary ataxia and peroneal muscular atrophy. Brain, 71, 416.

Teare, D. (1958). Asymmetrical hypertrophy of the heart in young adults. Brit. Heart J., $20,1$.

Whitfield, A. G. W. (1961). Familial cardiomyopathy. Quart J. Med., 30, 119. 